\title{
DOS NUEVAS HACHAS DE ÉPOCA TARDOANTIGUA PROCEDENTES DE LOS FONDOS DEL MUSEO DE GUADALAJARA (SIGLOS V-VI). CRONOLOGÍA Y CONTEXTO CRONOCULTURAL
}

\author{
TWO NEW AXES FROM LATE ANTIQUITY FROM THE FUNDS OF THE GUADALAJARA \\ MUSEUM $\left(5^{\mathrm{TH}}-6^{\mathrm{TH}}\right.$ CENTURIES). CHRONOLOGY AND CHRONOCULTURAL CONTEXT
}

\author{
POR \\ Raúl Catalán Ramos*, Enrique Daza Pardo** y Elena Vega Rivas ${ }^{* * *}$
}

\section{RESUMEN - ABSTRACT}

Este trabajo presenta dos hachas de hierro tardoantiguas inéditas depositadas en el Museo de Guadalajara que proceden de sendos hallazgos fortuitos realizados en el norte de la provincia. Ambos casos se adscriben a tipologías poco comunes en Hispania, ya que los paralelos más claros se encuentran fuera del ámbito peninsular. Dada su extremada rareza, su documentación y análisis proporciona tanto la ampliación del repertorio de elementos vinculados con el mundo militar tardorromano y altomedieval en el centro peninsular, como la movilidad y dispersión de tipos por toda Europa.

This work presents two previously unknown late roman iron axes deposited in the Museum of Guadalajara that come from two fortuitous findings made in the north of the province. Both cases are adscribed to rare typologies in Hispania, since the clearest parallels are all outside the peninsular sphere. Given its extreme rarity, its documentation and analysis confirms both the expansion of the repertoire of elements linked to the late-Roman and early medieval military world in the center of the Iberian Peninsula, and the mobility and dispersion of types throughout Europe.

\section{Palabras Clave - Keywords}

Hispania; Sigüenza; La Olmeda de Jadraque; Romanillos de Atienza; periodo tardorromano; siglo V; siglo VI; hacha; mundo funerario; armamento.

Hispania; Sigüenza; La Olmeda de Jadraque; Romanillos de Atienza; fifth century; sixth century; Late Roman period; axe; grave godos; weaponry.

\section{Cómo CITAR ESTE ARTículo / CitATION}

Catalán Ramos, R.; Daza Pardo, E. y Vega Rivas, E. (2021): «Dos nuevas hachas de época tardoantigua procedentes de los fondos del Museo de Guadalajara (siglos V-VI). Cronología y contexto cronocultural». Gladius, 41: 129-136. https://doi.org/10.3989/gladius.2021.07

\footnotetext{
* Asociación Zamoraprotohistórica, raulcatalanr@gmail.com / ORCID iD: https://orcid.org/0000-0003-1296-7414

** Investigador independiente, enriquedazapardo@gmail.com / ORCID iD: https://orcid.org/0000-0001-9370-7635

**** Gabinete de Arqueología y Patrimonio, evega@gabinetedearqueologia.com / ORCID iD: https://orcid.org/0000-00029870-9039
} 


\section{INTRODUCCIÓN ${ }^{1}$}

El estudio de la cultura material del final del mundo romano y del inicio del periodo medieval en el norte de la provincia de Guadalajara cuenta con abundantes lagunas, habiendo despertado escaso interés entre los investigadores a pesar de la trayectoria de publicación de hallazgos iniciada por H. Zeiss (1934). La aparición de la obra del investigador alemán puso de relieve tanto la presencia de diversas necrópolis de época visigoda como el carácter de los hallazgos que exponía, que eran fruto de una recuperación sin metodología arqueológica, que habían acabado en manos de coleccionistas, y de ahí, en los fondos de algunos museos provinciales españoles en los años 20-30 del siglo pasado.

En este sentido, y en un contexto actual, la necesidad de prestar atención a estos materiales sin contexto sigue siendo una realidad, habida cuenta la escasa nómina de intervenciones que han proporcionado contextos de esta cronología. En esta misma línea, el papel jugado por las instituciones que custodian este tipo de hallazgos sigue siendo primordial, no solo como meras depositarias de los materiales sino como lugares de investigación. El Museo de Guadalajara cuenta entre sus fondos con el depósito de varias colecciones privadas, que cuentan con un inventario y son conservadas de una forma científica y reglada. Las dos hachas a las que nos referiremos a lo largo del presente trabajo cuentan con una historia similar, procediendo ambas de hallazgos fortuitos, por lo que carecen de un contexto arqueológico que ayude a su caracterización, contextualización y datación.

La primera de las piezas, a la que denominaremos "Hacha 1" procede de la colección del Museo de Sigüenza depositada en el de Guadalajara junto con gran cantidad de piezas líticas y metálicas de diversa procedencia y cronología. El lugar de su hallazgo es discutido, pues se cree que puede proceder de La Olmeda de Jadraque, aunque también se valora que pudiera proceder de la vecina Imón, ambas en el valle del río Salado. La segunda pieza, "Hacha 2" procede de las colecciones del Museo de Atienza, en depósito en Guadalajara

\footnotetext{
${ }^{1}$ Queremos agradecer la gran disposición y la excelente ayuda prestada por el Museo de Guadalajara, en especial de Miguel Ángel Cuadrado y Fernando Aguado, para la consulta de sus fondos y el estudio contextualizado de estos dos objetos.
}

desde hace varios años. El conjunto del hallazgo se completa con útiles agrícolas de hierro, destacando una sítula de gran tamaño.

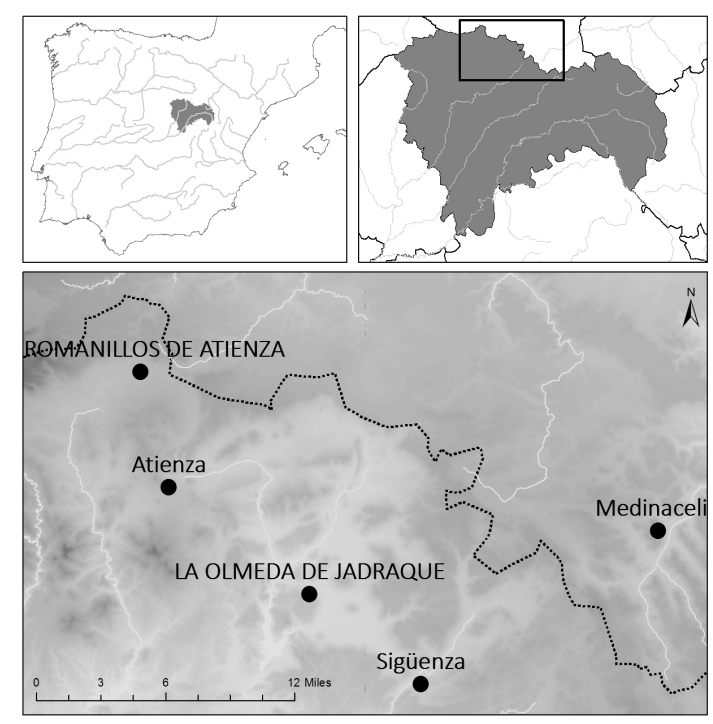

Figura 1. Localización de los hallazgos y de otros enclaves cercanos mencionados en el texto.

\section{EL ESTUDIO DE LA ANTIGÜEDAD TARDÍA EN EL NORTE DE GUADALAJARA}

La transición de la Antigüedad a la Edad Media, como todo tiempo de transición, es un momento de cambio, durante el cual las perduraciones de lo antiguo se mezclan con lo nuevo. Como decíamos anteriormente, el estudio de este periodo en el norte de Guadalajara ha sido, bastante poco cultivado. Desde el punto de vista historiográfico, los temas que han suscitado una mayor atracción para la investigación de este periodo han sido por un lado el trazado viario y las necrópolis tardorromanas y de época visigoda por otro.

Durante la Antigüedad Tardía el norte de Guadalajara se ubicaba en los confines de varios territoria de ciudades romanas, como Termes, Complutum u Occilis, lo que le confería un carácter marginal, solo iluminado por la presencia de diferentes rutas de comunicación de relevancia, de entre las cuales destaca la que comunicaba Augusta Emerita con Caesaraugusta, inmortalizada como la ruta XXIII del Itinerario de Antonino. Esta vía ya despertó el interés de José Cornide, quien realizó a finales del siglo XVIII viajes por La Alcarria y el valle del Henares en busca de su trazado y 
de la ubicación de los hitos a los que hacía referencia el citado itinerario (Vallejo, 1999). Un trabajo fundamental sobre las vías de comunicación en época romana es, aun con sus deficiencias, la obra de J. M. Abascal Palazón (1982). En ella se analizan todos los itinerarios históricos de la provincia a partir de los escasos hallazgos arqueológicos del momento y de las fuentes escritas. Este trabajo presta especial atención al citado Itinerario de Antonino para las rutas correspondientes al norte de Guadalajara y el Alto Henares. Con todo esto, pretendía presentar un panorama completo de toda la provincia, si bien no le fue posible, debido a la escasez de datos con los que contaba en aquel momento.

En lo que a las manifestaciones funerarias se refiere, habría que destacar los hallazgos relacionados con el contexto previo a los cementerios visigodos, como son la necrópolis de Aguilar de Anguita (siglo IV), excavada por Cerralbo a principios del siglo XX a la vez que excavaba el cementerio celtibérico (Pérez y Barril, 2010-2012), o la necrópolis de Herrería, de reciente publicación y datada en el siglo V (Cerdeño et alii, 2018). En cuanto a cronologías más recientes, el interés por las necrópolis de época visigoda, así como por los ajuares de sus tumbas, se ha centrado en el estudio de los objetos descontextualizados procedentes de las necrópolis de Alarilla y Palazuelos (Zeiss, 1934), y más tarde de Villel de Mesa (Martín y Elgorrieta, 1947). Las primeras excavaciones con metodología arqueológica no tuvieron lugar hasta los años 60 del siglo XX, cuando se intervino en Camino de la Barca, entre Azuqueca y Alovera (Vázquez de Parga, 1963; Alonso, 1978) y en la década siguiente en Trillo (Izquierdo e Izquierdo, 1977, 1977-1978; Izquierdo Bertiz, 1978; Cristóbal, 1981). Ya en el siglo XXI, se realizó la excavación de la necrópolis de El Tesoro-Carramantiel (Gualda), primera con metodología actual y que proporcionó resultados muy interesantes sobre el final del mundo visigodo (Cuadrado, 2002). Más recientemente se ha intervenido en la necrópolis visigoda de "La Guilanera" en Armuña de Tajuña en 2005 (Escobar y García, 2010) y en la necrópolis de Cubillejo de la Sierra, localizada en 2006 en el marco del proyecto de investigación del oppidum de Los Rodiles (Cerdeño et alii, 2015).

A modo de síntesis de los trabajos antiguos y modernos sistemáticos, unidos a los hallazgos fortuitos, depositados en los fondos de los museos de Atienza y Guadalajara fundamentalmente, se realizó una revisión de conjunto para ofrecer, al menos, una distribución cronológica entrelazando las aportaciones de la estratigrafía y la tipología, encaminada a vislumbrar la evolución del poblamiento, su implantación y la realidad social de sus gentes, que subyace en el estudio de los cementerios y los ajuares funerarios que los acompañaban (Daza y Catalán, 2011).

La nómina de yacimientos en el Alto Henares de cronología tardorromana, son conocidos exclusivamente por prospección y, salvo algunos casos, se datan de fines del siglo IV, no mostrando aparente "continuidad" con el siglo V. Estos yacimientos son Fuente del Cuerno (Romanillos de Atienza), Barranco Escobar (Atienza), La Asomadilla (Riofrío) y El Tesoro (Bochones) (Iglesias, 1993). Se trata de un momento en el que los espacios de hábitat en llano comienzan a simultanearse con lugares en altura, con el fin de separarse de los valles y las rutas de comunicación por ser espacios más conflictivos. Estos encumbramientos tardorromanos reocuparon lugares de hábitat prerromano (Gamo, 2013), comenzando a forjarse un paisaje habitado aún más atomizado de lo que venía siendo en esta zona de sierra, donde las alturas y fortificaciones van a marcar la composición de este territorio hasta bien entrado el Medievo (Daza, 2008). A modo de ejemplo podemos indicar el enriscamiento que se produce en Atienza, tanto en el propio espacio del castillo (Iglesias, 1993: 105) como en el Cerro del Padrastro (Valiente, 1992).

A pesar de esta ruralización y del paulatino encumbramiento de las poblaciones, el Alto Henares conservó una población significativa que fue cristianizándose paulatinamente (Daza, 2007a; 2007b). La presencia de un obispo en Segontia es el claro síntoma de la significativa ocupación del territorio y la generación de un espacio vinculado a la cabeza de la diócesis, sufragánea de la metropolitana Toledo. El primer obispo seguntino mencionado en las fuentes es Protógenes que asistió al III Concilio de Toledo celebrado en mayo de 589 (Vallejo, 1993), aunque según García Moreno sería anterior, ya que en el II Concilio de Toledo de 531 se cita a los cuatro obispos de Carpetania et Celtiberia (García Moreno, 1974: n. 355). Los siguientes obispos que aparecen en los sucesivos concilios son: Hildisclus (IV, V y VI), Witericus (VII, VIII, IX y X), Egica (XI), Ella (XII, XIII y XIV) y Gundericus (XV y XVI) (Vives, 1963). Otro síntoma de la cristianización de este territorio es la presencia de diferentes eremitas y anacoretas que, escapando de la sociedad, ocupaban 
cuevas artificiales y, a su muerte, eran enterrados en ellas. Desconocemos si se organizaron en comunidades, pero al menos son un reflejo de la extensión tardía del cristianismo en un espacio de baja densidad demográfica (Daza, 2008).

Este panorama pone de relieve que el Alto Henares, pese a tratarse de una zona marginal en estos momentos, por su carácter de zona de paso, estuvo perfectamente imbricada en los cambios sociales y en el trasiego comercial de este momento transicional, lo que vendría avalado por la gran cantidad de hallazgos, incluso algunos, como los que nos ocupan en este trabajo, tan escasos y con paralelos tan lejanos.

\section{CARACTERIZACIÓN, PARALELOS Y CRONOLOGÍA}

En primer lugar, realizaremos la descripción y caracterización del Hacha 1, procedente del entorno de Sigüenza, probablemente de La Olmeda de Jadraque, ya que proponemos que su cronología es anterior a la de la pieza procedente de Romanillos de Atienza (Hacha 2), que abordaremos en la segunda parte de este trabajo.

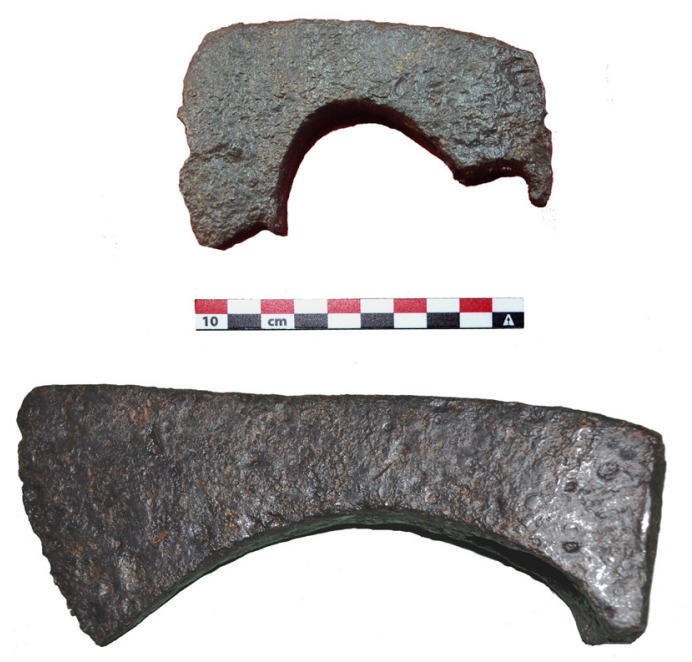

Figura 2. Fotografía de las hachas estudiadas. Fotografía: Elena Vega.

La pieza en cuestión presenta unas dimensiones de $11 \mathrm{~cm}$ de longitud total y una hoja cuyo filo apenas supera los $7 \mathrm{~cm}$ (Figs. 2 y 3), lo que da lugar a una pieza de tamaño relativamente pequeño. El dorso presenta una ligera curvatura, que genera que el punto de arranque de la hoja se sitúe ligeramente elevado sobre el eje del ojo de enmangue superior. Por su parte, el filo muestra un notable desarrollo que lo hace sobresalir del cuerpo del hacha por su parte inferior. La zona ventral presenta una marcada curvatura, y en la parte opuesta al filo el enmangue cuenta con un talón protector que se extiende cubriendo la parte superior del asta, y para añadir más protección, el enmangue va "encastrado" mediante una prolongación de la cara ventral que se une con el talón. Este tipo de rasgos -sobre todo la destacada curvatura ventral y la prolongación del filo-, son relativamente frecuentes en determinados modelos de hacha de los siglos VI y VII, como ponen de manifiesto ejemplares como el recuperado en la cueva de Los Goros o ciertos tipos también presentes en la necrópolis alavesa de Aldaieta (Azkárate, 1999). Sin embargo, en lo que respecta a los aspectos puramente morfológicos, el ejemplar que puede considerarse el paralelo más cercano no se encuentra en ámbito peninsular, sino en el centro de Francia, en la sepultura tardorromana de Saint-Rimay (Fig. 4), calificada como tumba de guerrero por H. W. Böhme en su trabajo sobre las necrópolis entre el Elba y el Loira (Böhme, 1974).

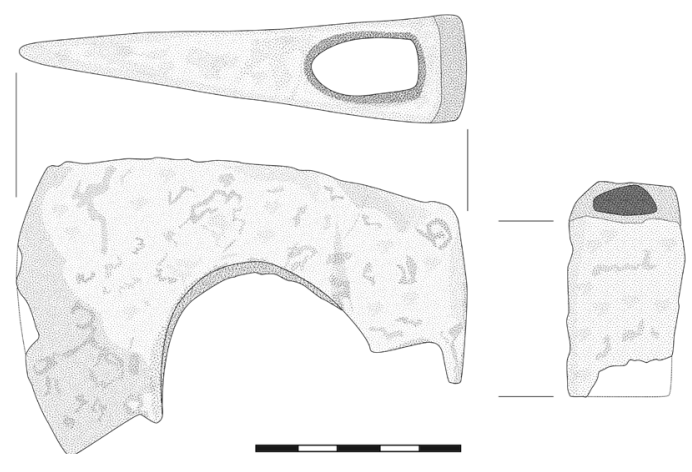

Figura 3. Dibujo del hacha número 1, depositada en el Museo Guadalajara y procedente, probablemente, de La Olmeda de Jadraque. Dibujo: Elena Vega.

Como se puede ver en una comparación detallada de ambas piezas, el parecido entre ellas es más que destacable, ya que sus rasgos esenciales (fundamentalmente las curvaturas tanto del dorso como de la zona ventral, así como la presencia de talón protector en el enmangue y, sobre todo, el "encastre" del mismo) ponen de manifiesto que nos encontramos ante un mismo tipo de hacha, que se diferencia con claridad de otros modelos contemporáneos que se han pro- 
puesto como paralelos para el ejemplar francés, como el recuperado en la necrópolis de Septeuil, que a nuestro juicio parece mucho más tardío (Barat et alii, 2001). Dadas sus características, hay que señalar que ambos ejemplares parecen muy próximos a la familia de las hachas barbadas de origen germánico, cuya presencia en la península se reduce en este momento a una serie de ejemplares más tardíos recuperados en Puig Rom.

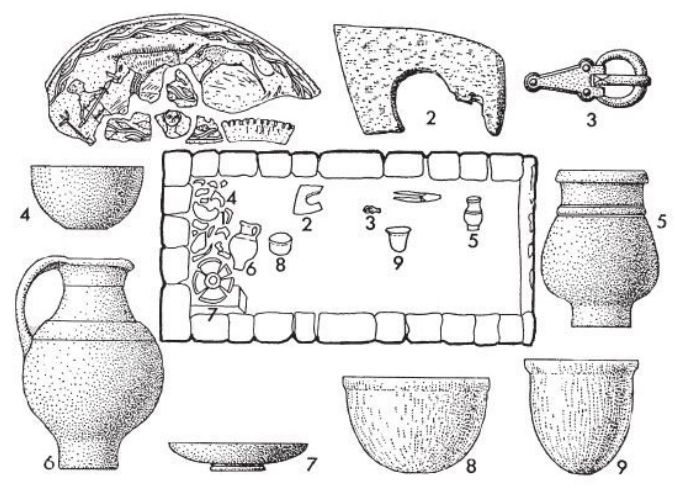

Figura 4. Hacha y elementos de ajuar de la tumba tardorromana de Saint-Rimay, Francia (Böhme, 1974).

Por lo que respecta al Hacha 2, ejemplar procedente con seguridad de Romanillos de Atienza, aun compartiendo alguna de las características con el Hacha 1 (como el talón protector en la zona inferior del enmangue), tiene rasgos que difieren de aquella y que permiten situarla en una horquilla cronológica algo más moderna, ya dentro del siglo VI avanzado. La primera diferencia es su tamaño ya que, frente a las modestas dimensiones de la pieza seguntina, la de Romanillos es mucho mayor y aún más sólida (Figs. 2 y 5).

La longitud total son $21 \mathrm{~cm}$, con un filo de 8 . El dorso presenta una ligera curvatura, que genera un perfil en forma de ' $S$ ' muy sutil, lo que es una de las características definitorias de las franciscas. Esta curvatura se acentúa ligeramente en la zona más próxima al arranque del filo, y aunque este se ensancha hacia la zona inferior, no llega a adquirir el aspecto de "barba" que posee el ejemplar de Sigüenza, ya que la curva ventral es mucho más suave. Por el contrario, como se ha indicado, en la zona del enmangue si presenta el característico talón de las piezas de cronología merovingia, lo que unido a la configuración de las curvas ventrales y dorsales permite incluir la pieza dentro del amplio grupo de modelos derivados de las franciscas, tal y como se viene definiendo en las tipologías continentales (Legoux et alii, 2009).

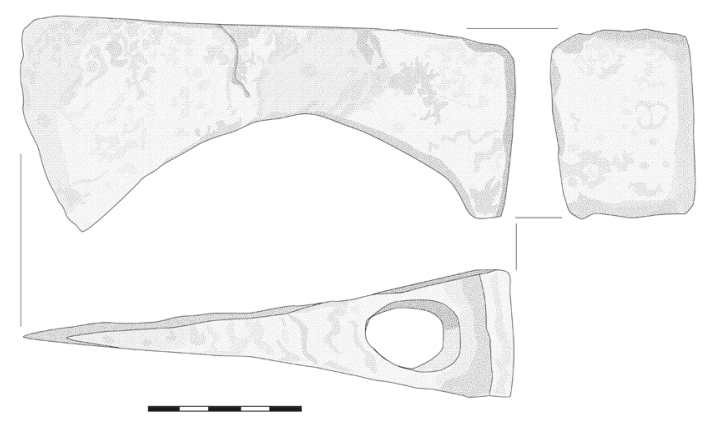

Figura 5. Dibujo del hacha número 2, depositada en el Museo Guadalajara y procedente de Romanillos de Atienza. Dibujo: Elena Vega.

Como resultado, el número de paralelos que se pueden encontrar para este ejemplar es significativamente más numeroso que para la pieza de Sigüenza, destacando dentro la península las hachas recuperadas en las sepulturas B 48-53 y B-68 de Aldaieta (Azkarate, 1999) y el ejemplar procedente de la necrópolis de Sasbach (Alemania), dentro ya del ámbito merovingio-alamán (Fingerlin, 1991), que pasa por ser uno de los ejemplares más cercanos dada su morfología (Fig. 6). A partir de su fisonomía y de los paralelos indicados, esta pieza puede situarse sin problema en una horquilla cronológica comprendida entre los años 530 y 600 , ya que además en muchas ocasiones se ha podido constatar su asociación a guarniciones de cinturón escutiformes y derivadas, que vienen fechándose con bastante seguridad dentro del periodo indicado.

No obstante, es necesario recalcar que los marcos cronológicos indicados para ambos ejemplares están muy mediatizados por los contextos funerarios, ya que constituyen hasta la fecha la gran mayoría de hallazgos de este tipo de piezas. Como consecuencia, la cronología real puede ser más amplia, pues los depósitos fúnebres no pueden considerarse un reflejo exacto de la cultura material de cada momento, ya que en ocasiones se excluyen determinados elementos que sí se localizan en contexto de hábitat, pero que no encajan con el discurso funerario que se busca elaborar mediante los ajuares asociados a los difuntos de este periodo, como veremos más adelante. 

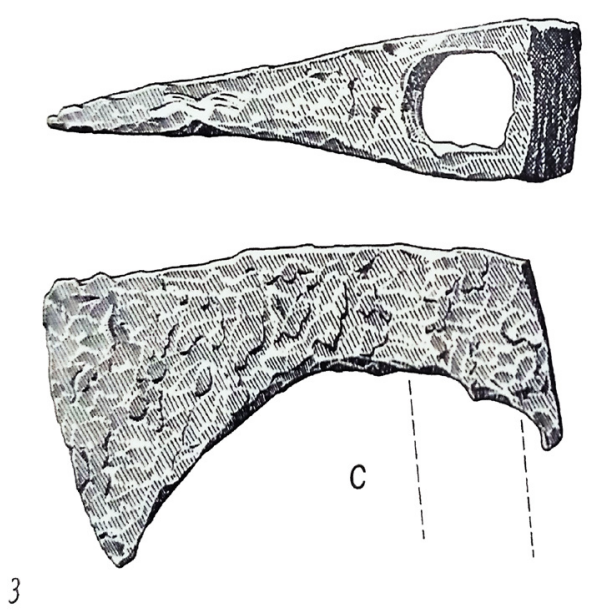

Figura 6. Hacha recuperada en enterramiento masculino de Sasbach, Friburgo, Alemania (Fingerlin, 1991).

\section{DISCUSIÓN: ¿QUÉ APORTA AL DEBATE SOBRE EL ARMAMENTO DE ÉPOCA VISIGODA LA PRESENCIA DE ESTE TIPO DE HACHAS EN LA MESETA SUR?}

Los hallazgos de Romanillos de Atienza y La Olmeda de Jadraque vienen a sumarse al reducido grupo de hachas localizadas en la península que pueden fecharse en los siglos V y VI, cuyo número total apenas supera los cuarenta ejemplares, $y$ de los cuales la gran mayoría procede del entorno de lo que se ha venido a denominar «necrópolis cispirenaicas occidentales» (Azkarate, 20052006). Fuera de este ámbito, su presencia se reduce a menos de media docena de piezas, entre las que se pueden contar los ejemplos de Taniñe o la francisca localizada en Bujalance (Soria y Córdoba, respectivamente), y determinadas piezas localizadas en la franja cantábrica como la recuperada en la cueva de Los Cirrios (Cantabria).

Teniendo en cuenta este dato, la documentación de dos nuevas piezas que además vienen a situarse fuera de la zona en la que se concentran los hallazgos es destacable no solo desde el punto de vista cuantitativo, sino sobre todo por las implicaciones que tiene este dato a la hora de establecer la interpretación cronocultural de las mismas. Como se ha indicado, la morfología de las piezas permite establecer paralelismos claros con determinados modelos de hacha existentes en el continente en el periodo reseñado, lo que permite paliar en buena medida el handicap de la pérdi- da de contexto arqueológico, y establecer no solo una referencia cronológica, sino también cultural. $\mathrm{Su}$ localización fuera de las zonas de influencia y contacto directo con el ámbito franco viene además a relativizar la lectura de estos elementos en sentido estrictamente etnicista, ya que en muchos casos se ha entendido su presencia como el testimonio de una influencia política y cultural merovingia directa en determinadas zonas de la península, contrapuesta a las coordenadas implícitas en las estructuras de poder visigodas radicadas en el centro de la península. El hallazgo de este tipo de materiales en la zona indicada viene a cuestionar este enfoque, y por el contrario viene a poner de manifiesto una lectura mucho más abierta, en la que además se vienen a poner en valor datos aportados por las fuentes coetáneas.

Como se ha indicado en varios trabajos acerca del armamento de este periodo, las armas no pasan por ser un buen marcador étnico (Pohl, 1998; Catalán, 2015), ya que las más eficaces se adoptan de forma rápida, si ello es posible, mientras que aquellas que quedan obsoletas suelen desaparecer con la misma celeridad, por una mera cuestión de supervivencia, salvo en contadas ocasiones en las que los aspectos ideológicos se imponen a los meramente pragmáticos. Teniendo esto en cuenta, no parece apropiado vincular el origen de las hachas de Guadalajara de forma exclusiva con una supuesta influencia franca, y mucho menos considerarlas como testimonios materiales de este entorno cultural. En primer lugar, hay que tener en cuenta que los estudios sobre armamento llevados a cabo recientemente en el continente vienen a poner de manifiesto que el origen de las franciscas se encuentra en los modelos romanos tardíos de dorso curvo (Legoux et alii, 2009), y que el uso de hachas barbadas ya se documenta entre las legiones romanas en momentos tan tempranos como el siglo III, como vienen a demostrar los ejemplares recuperados en los grandes depósitos del Rin, entre los que se han hallado ejemplares marcados con los cuños de diversas legiones.

Si tenemos en cuenta el enorme peso que el ejército romano tuvo en el desarrollo tanto de los ejércitos francos como visigodos, es muy factible que el origen de los modelos de hachas en uso entre ambos fuera común, si bien a la luz de los testimonios relacionados con la arqueología funeraria se viene a poner de manifiesto una mayor importancia entre los merovingios. Esta situación, en la que el hacha parece tener un protagonismo muy superior para los francos que el otorgado dentro del ámbito cultural visigodo se puede verificar en San Isidoro, cuando en las Etimologías indica que 
a las hachas en el siglo VI se les acabo por denominar franciscas a raíz del uso extensivo que los francos hacían de ellas en el campo de batalla, lo que viene a corroborar lo que parece documentarse en la arqueología funeraria de buena parte de Francia. Así mismo, en ese mismo pasaje, el obispo sevillano deja claro que estas hachas eran conocidas y empleadas con normalidad por los ejércitos visigodos (quas Hispani ab usu Francorum per derivationem Franciscas vocant).

Teniendo en cuenta estos datos, pensamos que es razonable interpretar que el hacha de Romanillos, que como hemos visto ha de situarse dentro del siglo VI, es más bien un testimonio del uso de este tipo de elementos de forma normalizada dentro del ámbito visigodo, con una relación en todo caso tangencial con el mundo merovingio. No obstante, dada la ausencia de contexto tampoco puede descartarse completamente que se trate de una importación desde la Galia merovingia, ya que, aunque ocasionales, se pueden considerar como tales las fíbulas de Gomará y Deza o la placa de cinturón aquitana recuperada en Barajas, por mencionar solo algunos ejemplos.

Por el contrario, a partir de los paralelos manejados, proponemos insertar la pieza de La Olmeda de Jadraque dentro los parámetros de la tradición tardorromana, sobre todo teniendo en cuenta los elementos que acompañaban el ajuar de la tumba de Saint-Rimay, -que pasa por ser el mejor paralelo para la misma-, y entre los que se incluyen el plato de vidrio decorado y las distintas producciones cerámicas romanas, asociadas a los talleres imperiales del norte de la Galia.

A tenor de su morfología, este tipo parece cercano a los bartaxt o hachas barbadas, que como se ha señalado anteriormente, es un modelo que ya estaba en uso entre los legionarios de la segunda mitad del siglo III, muy posiblemente con una finalidad diversa pero también utilizado como arma². De acuerdo con estos datos, pensamos que este ejemplar debe de ser considerado como una muestra de la cultura material romana de finales del siglo IV o inicios del V, sin la necesidad de vincular su origen con el mundo germánico más que de una manera muy tangencial, ya que además la presencia de hachas formando parte de los ajuares funerarios en contextos tardorromanos en Hispania está bien documentada en necrópolis como Taniñe u Hornillos del Camino (Pinar, 2017).

2 Amiano Marcelino describe el uso de hachas por parte de las tropas romanas en la batalla de Adrianopolis, hacia finales del siglo IV (Rerum gestarum libri XXXI, XXXI, 13.3).

\section{CONCLUSIÓN}

En conclusión, consideramos que la documentación de ambas hachas contribuye, no solo a mejorar el conocimiento de los fondos del Museo de Guadalajara y de la historia de la provincia en época tardorromana, sino también a mejorar los conocimientos existentes acerca de la distribución de este tipo de elementos en ámbito hispano. Esto permite establecer nuevas interpretaciones respecto a su contexto cultural, que restan en buena medida el excesivo peso que la arqueología funeraria ha tenido hasta la fecha a la hora de establecer marcos interpretativos para este tipo de elementos. Por el contrario, planteamos que se pueden entender ambas piezas como parte de las dinámicas culturales presentes en la península sin tener que explicarlas necesariamente como huellas de una presencia foránea, sino como un testimonio de la participación de Hispania en los mismos procesos de transformación que se detectan en Europa occidental tras la desintegración del aparato político romano.

\section{BIBLIOGRAFÍA}

Abascal Palazón, J. M. (1982): Vias de comunicación romanas en la provincia de Guadalajara. Guadalajara, Diputación provincial.

Alonso, M. ${ }^{\text {a }}$ A. (1978): «Camino de la Barca (Azuqueca - Alovera)». Wad-al-Hayara, 5: 267-268.

Azkárate Garai-Olaun, A. (1999): Necrópolis tardoantigua de Aldaieta (Nanclares de Gamboa, Alava). 1: Memoria de la excavación e inventario de los hallazgos. Serie Memorias de yacimientos alaveses, 6. Vitoria-Gasteiz, Diputación Foral de Álava.

Azkárate Garai-Olaun, A. (2005-2006): «Sobre los orígenes cronológicos de los cementerios cispirenaicos de época tardoantigua». Munibe, 57/2: 405-417.

Barat, Y.; Langlois, M. y Bricon, D. (2001): «Habitats et nécropoles du haut Moyen-Âge en vallée de Vaucouleurs (sites de Septeuil et Villette, Yvelines)». Revue archéologique du Centre de la France, 40: 133-165. https://doi.org/10.3406/racf.2001.2878

Böhme, H. W. (1974): Germanische grabfunde des 4. bis 5. jahrhunderts zwischen unterer elbe und loire Studien zur Chronologie und Bevölkerungsgeschichte. Múnich, C. H. Beck.

Catalán Ramos, R. (2015): «Elementos de armamento y mundo funerario en Hispania (siglos V-VIII)», J. A. Quirós Castillo y S. Castellanos (coords.): Identidad y etnicidad en Hispania: propuestas teóricas y cultura material en los siglos V-VIII. Bilbao, Universidad del País Vasco: 291-312.

Cerdeño, M. a L.; Gamo, E. y Chordá, M. (2015): «Una nueva necrópolis de época visigoda en Cubillejo de la Sierra (Guadalajara, España)», G. Branco, L. Ro- 
cha, C. Duarte, J. de Oliveira y P. Bueno Ramirez (eds.), Arqueologia de Transição: O mundo funerario. Evora, CHAIA Centro de História de Arte e Investigação Artística Universidade de Évora: 217223.

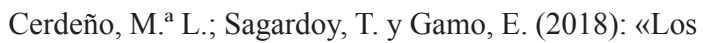
enterramientos tardorromanos de Herrería V (Guadalajara, España)». Boletín del Museo Arqueológico Nacional, 37: 361-370.

Cristóbal Rodríguez, R. (1981): «Nuevo ajuar funerario de la necrópolis visigoda de Trillo». Wad al-Hayara, 8: 425-430.

Cuadrado Prieto, M. A. (2002): «El yacimiento hispano-visigodo de El Tesoro-Carramantiel, Gualda (Cifuentes, Guadalajara)», E. García-Soto Mateos y M. A. García Valero (eds.), Actas del primer simposio de arqueología de Guadalajara (Sigüenza, octubre de 2000). Guadalajara, Ayuntamiento de Sigüenza: 501-512.

Daza Pardo, E. (2007a): «La edilicia rupestre en el norte de Guadalajara. Hábitat y eremitismo en la transición de la Antigüedad a la Edad Media». Codex Aquilarensis, 23: 9-27.

Daza Pardo, E. (2007b): «Elementos para el estudio de la arqueología altomedieval en la sierra norte de Guadalajara. Monacato, edilicia y poblamiento», Monasteria et territoria. Elites, edilicia y territorio en el Mediterráneo medieval (ss. V-XI). Madrid, British Archaeological Reports (IS): 399-408.

Daza Pardo, E. (2008): «Los castillos olvidados. El papel de los asentamientos fortificados en altura en la génesis del poblamiento altomedieval del valle del Henares (ss. VII-XII)». Castillos de España, 148: 13-25.

Daza Pardo, E. y Catalán Ramos, R. (2011): «Las necrópolis de época visigoda de la provincia de Guadalajara. Una revisión crítica». Gausac, 3435. Monográfico, J. Pinar Gil y T. Juárez Villena (eds.), Contextos funeraris a la Mediterrània nordoccidental, Mesa Redonda. San Cugát del Vallès (Octubre 2009): 131-143.

Escobar Fernández, R. y García González, F. J. (2010): «La necrópolis visigoda de "La Guilanera", Armuña de Tajuña (Guadalajara)», A. Madrigal Belinchón y M. Perlines Benito (coords.), Actas de las II Jornadas de Arqueología en Castilla-La Mancha (Toledo, 2007). Toledo, Junta de Comunidades de Castilla La Mancha / Diputación de Toledo: 45-46.

Fingerlin, G. (1991): «Neue Grabungen im Reihengräberfeld von Sasbach a.K., Kreis Emmendingen». Archäologische Ausgrabungen in BadenWürttemberg 1990: 183-187.

Gamo, E. (2013): «Cuevas y alturas: reocupación de hábitats prerromanos en el Bajo Imperio en la provincia de Guadalajara», D. Álvarez, R. Sanz y D. Hernández (coords.), El espejismo del bárbaro. Ciudadanos y extranjeros al final de la Antigüedad. Castellón de la Plana, Universidad Jaume I: 213240 .
García Moreno, L. A. (1974): Prosopografía del Reino Visigodo de Toledo. Salamanca, Universidad de Salamanca.

Iglesias Vecino, E. (1993): «La romanización en la comarca de Atienza», J. Valiente Malla (ed.), La Celtización del Tajo Superior. Alcalá de Henares, Universidad de Alcalá: 79-106.

Izquierdo Benito, R. e Izquierdo Bértiz, J. M. a (1977): «Excavaciones en la necrópolis altomedieval de Trillo (Guadalajara)». Wad al-Hayara, 4: 261-265.

Izquierdo Benito, R. e Izquierdo Bértiz, J. M. a (19771978): «Excavaciones en la necrópolis altomedieval de Trillo (Guadalajara), 1972». Noticiario arqueológico hispánico, 5: 403-408.

Izquierdo Bertiz, J. M. (1978): «Trillo (1977)». Wad alHayara, 5: 273-275.

Legoux, R.; Perin, P. y Vallet, F. (2009): Chronologie normalisée du mobilier funéraire mérovingien entre Manche et Lorraine ( $3^{\mathrm{a}}$ edición revisada y corregida). Bulletin de liaison de l'Association française d'Archéologie mérovingienne, s/n. Saint-Germainen-Laye, Association française d'archéologie mérovingienne.

Martín, M. y Elgorrieta, A. (1947): «El cementerio visigodo de Villel de Mesa». Cuadernos de Historia Primitiva, 2: 54-56.

Pérez, F. y Barril, M. (2010-2012): «El cementerio tardorromano de Aguilar de Anguita y la problemática de las necrópolis con ajuares tipo "Simancas - San Miguel del Arroyo"». Sautuola, XVI-XVII: 215237.

Pinar Gil, J. (2017): La cronologia dei corredi funerari di epoca visigota in Spagna e Francia meridionale: peculiarità, problemi, soluzioni e stress testing. Roma, BraDypUS.

Pohl, W. (1998): «Telling the difference: signs of ethnic identity», en W. Pohl y H. Reimitz (eds.), Strategies of Distinction: The Construction of the Ethnic Communities, 300-800. Serie Transformation of the Roman World, 2. Leiden, Brill: 17-69

Valiente, J. (1992): «El Cerro Padrastro de Santamera y la protohistoria del valle del Henares», J. Valiente Malla (ed.), La Celtización del Tajo Superior. Alcalá de Henares, Universidad de Alcalá: 11-44.

Vallejo Girvés, M. (1993): «Notas sobre el Obispado de Segontia en época visigoda». Wad al-Hayara, 20: 65-375.

Vallejo Girvés, M. (1999): Los Viajes de Cornide por la Alcarria. Guadalajara, Aache.

Vázquez de Parga, L. (1963): «Excavaciones arqueológicas en Azuqueca (Guadalajara)». Noticiario arqueológico hispánico, VII: 224-228.

Vives, J. (1963): Concilios visigóticos e hispano-romanos. Madrid, Consejo Superior de Investigaciones Científicas, Instituto Enrique Flórez.

Zeiss, H. (1934): Die Grabfunde aus dem spanische Westgotenreich. Berlín y Leipzig, De Gruyter. 